\title{
Introduction of the Takizawa Method and Motivative Exercise
}

\author{
Yoshiko Morita, MD \\ Department of the rehabilitation Medicine, Okayama rehabilitation hospital (Japan)
}

\begin{abstract}
Our research has a long history. Research began by the lawmaker of the local governing having recognized the result of the community rehabilitation in 1987. Then, the Takizawa method rehabilitation was performed at the inpatient of the hospital for the bedridden elderly ${ }^{122}$. We verified the fact that the elderly inpatients of the terminal stage who had been admitted to a hospital in the state of bedridden re-gained the $1 / 3$ walk as a result of an investigation of a medical chart and factual survey ${ }^{34 / 5)}$. And the orthopedists of Fujisawa-Shi described the first fact paper with Takizawa, and it was published6). We introduce you the research done on the Geriatric Health Services Facility Shonan-no-oka as a supplementary examination of this fact today. The doctors and the physiotherapists did this research for one year. The number of those who regained the walk was 35 as the result ${ }^{7}$. And the number of those who could walk was seven at the beginning. Moreover, we admitted the significant effect to the item of a walk and a toilet about an FIM score in the statistical evaluation ${ }^{8}$. According to video televising, we explain the actual condition of the Takizawa method, technique of having explained this fact, and introduce it.
\end{abstract}

Keywords: Takizawa method, Motivative exercise, inpatient, weak elderly, kinetic rehabilitation

Reference

1) Takizawa $S$. and 21st-century rehabilitation research society, The re-acquisition of walking of the bedridden elderly. Civil Publishing Inc. Fujisawa. 1996 (JP).

2) TAKIZAWA, Shigeo, et al: Method for managing exercise for function recovery and muscle strengthening, US Patent $7,153,250,2006$

3) S. Takizawa, T. Kimura, H. Kijima, Y. Okamoto, K. Nagaoka, Y. Morita, S. Endo, H. Nagasawa, M. Makita, K. Takizawa, Re-acquirement of Walking from Bedridden by the Motivative Exercise and Takizawa Method and Proposition of the Solution to the Aging Crisis, BIOPHILIA Vol. 2015 (2015) No. 1 Memorial Edition for the Linking ISSN Registration p. 12-18, http://doi.org/10.14813/ibra.2015.12.

4) Takizawa, S, Kimura, T, Kijima, H, Okamoto, Y, Nagaoka, K, Morita, Y, Endo, S, Nagasawa, H, Makita, M, Takizawa, K "Biophilia Rehabilitation and Proposition of the solution to the aging crisis" and ISPRM. (1) Ferrarese, Monduzzi Editore, 729-736. (2001).

5) S. Takizawa, T. Kijima, H. Kijima, K. Nagaoka, S. Kanai, Y. Morita, H. Nagasawa, S. Endo, K. Takizawa, Ambulation from Bedridden - Patient with Double Hemiplegia, BIOPHILIA Vol. 2015 (2015) No. 1 Memorial Edition for the Linking ISSN Registration p. 16-18 http://oi.org/10.14813/ibra.2015.16

6) Hideo Kijima, Kenji lizuka, Shigenobu Imai, Toshiaki Kato, Hitomi Watanabe, Shiro Kanai, Kyoko Takizawa, Shigeo Takizawa, The Rehabilitation Trial for the acquisition of walking from bedridden at the bedridden elderly hospital. The Journal of the Japanese Clinical Orthopaedic Association. Vol. 23. NO. 2 JUNE. 1998: 186-191 (JP).

7) Yoshiko Morita, Implementation result evaluation of the Takizawa method and Motivative exercise, Qualitative evaluation implementation result of the study of the Association for Technical Aids 2000 year Grant, The surveillance study for elderly lower-limb Fracture patient's improvement in ADL, and independent living, Proceedings of the Medical Research of the Biophilia Rehabilitation Academy, section meeting, 2013/03/01, p 290, http://doi.org/10.14911/biophilia.2013.2.0_290.

8) Kenji Ushizawa, Shigeo Takizawa,et al, Statistical Evaluation of Rehabilitation to the Disabled Elderly Based on the Takizawa Method、BIOPHILIA Vol. 2015 (2015) No. 1 Memorial Edition for the Linking ISSN Registration p. 1927, $1^{\text {st }}$ publication Biophilia Rehabilitation Journal, 2-1:71-80, 2004. http://doi.org/10.14813/ibra.2015.19 